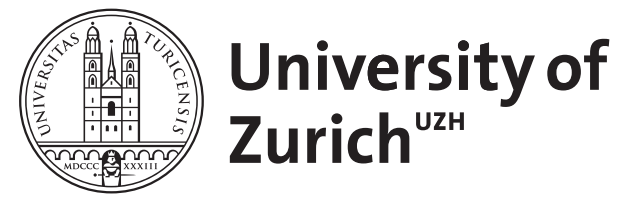

Zurich Open Repository and Archive

University of Zurich

University Library

Strickhofstrasse 39

CH-8057 Zurich

www.zora.uzh.ch

Year: 2010

\title{
Über ärztliche Kommunikationsformen - nicht nur bei unseren nördlichen Nachbarn
}

Wolff, Eberhard

Posted at the Zurich Open Repository and Archive, University of Zurich ZORA URL: https://doi.org/10.5167/uzh-38834

Journal Article

Originally published at:

Wolff, Eberhard (2010). Über ärztliche Kommunikationsformen - nicht nur bei unseren nördlichen Nachbarn. Schweizerische Ärztezeitung, 91(36):1406. 


\section{Über ärztliche Kommunikationsformen - nicht nur bei unseren nördlichen Nachbarn}

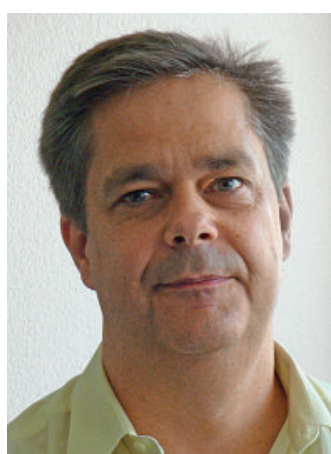

Eberhard Wolff
Wie schreibt man über einen verstorbenen Ärztefunktionär? Einen Abriss seines Lebens? Eine subjektive Erinnerung, wie man ihn wahrgenommen hat? Eine Würdigung seiner Verdienste?

Wie schreibt man über einen verstorbenen hohen deutschen Ärztefunktionär, dem eine schlimme NaziVergangenheit zumindest vorgeworfen wird? Der Streit um einen Nachruf auf Hans Joachim Sewering, bei dem die «dunkle Seite» seiner Biographie mit keinem Wort erwähnt wurde (vgl. den Beitrag auf S. 1402), zeigt, welche unterschiedlichen Vorstellungen über diese Frage herrschen. Jenseits der ohnehin gegebenen politischen Sprengkraft des Themas macht der Fall offensichtlich, dass die Art, wie heute auch in der Ärzteschaft öffentlich kommuniziert wird, im Wandel begriffen ist.

Es gab einmal eine Zeit, da inszenierten sich Ärzte gerne als Helden im Kampf um die Rettung der leidenden Menschheit oder als selbstaufopfernde Samariter. Und so sahen auch ihre Nachrufe aus. Die ältere Medizingeschichtsschreibung hat kräftig daran mitgearbeitet. Und es gab einmal eine Zeit, in der galt es als Gesetz, in Nachrufen nur das Positive zu erwähnen. Ärzten wurde in der Öffentlichkeit kaum als «normaler» oder gar fehlbarer Menschen gedacht (ein Mengele einmal ausgenommen). Die Würdigung Sewerings im Deutschen Ärzteblatt ist mehr oder weniger dieser Tradition verpflichtet.

Sicher, das Prinzip «De mortuis nil nisi bene» erinnert daran, dass sich Tote nicht mehr wehren können. Doch Nachrufe mit steifen Würdigungen formeller Verdienste werden heute noch deutlicher als das erkannt, was sie sind: hochformalisierte Texte wie so manche Erst-August-Ansprachen, die mehr Symbol darstellen als informieren. Solche Würdigungen werden in der Tat nicht dafür geschrieben, um in Leserbriefen diskutiert zu werden. In unserer Kommunikationsgesellschaft werden herkömmliche, starre Nachrufe aber immer weniger für ausreichend befunden und schon gar nicht mit diesem historischen Hintergrund.

Die anderen Reaktionen auf Sewerings Ableben sind ein Paradebeispiel für das, was sich geändert hat. Ein Autor spricht neben der Würdigung auch die «dunklen» Seiten Sewerings an, signalisiert seine Distanz zum Verstorbenen aber vor allem mit dem Verzicht auf ein positives Adjektiv. Das ist ein vorsichtiger Regelbruch. Formalisierte Textgattungen lassen eben wenig Spielräume, wie ein Arbeitszeugnis, in dem nur durch Weglassung oder codierte Formulierungen implizite Kritik geübt werden kann.

Kein Wunder, dass Medizinhistoriker allergisch auf Ärztenachrufe ganz alten Stils reagieren. Sie möchten nicht mehr Claqueur und immer weniger Richter spielen. Sie fordern eine breite historische Information über den Verstorbenen - als Teil einer Wissensgesellschaft. Der von ihnen erkämpfte Leserbrief als «Gegendarstellung» ist nicht nur das «Nein» einer sich seit langem neu definierenden Wissenschaft, die nicht rechtfertigen und «grosse Ärzte» würdigen, sondern analysieren will. Er ist auch Ausdruck eines anderen, offeneren Stils öffentlicher Medizinkommunikation.

Unsere Art, öffentlich zu reden, ist schon länger in Bewegung. Bereits im 18. Jahrhundert machte sich in Europa der frei räsonierende Diskurs des Bürgertums gegen die Verlautbarungs-Öffentlichkeit der oft monarchischen Obrigkeiten breit. Kein Geringerer als der Philosoph Jürgen Habermas hat dies 1962 in seinem Buch «Strukturwandel der Öffentlichkeit» beschrieben. Nun kratzt dieser Prozess an den letzten Bastionen formalisierter Öffentlichkeit.

Auch in der Schweiz ist kürzlich ein hoher Ärztefunktionär gestorben: Hans Heinrich Brunner. Ludwig T. Heuss nannte ihn in seinem Nachruf [1] in der Schweizerischen Ärztezeitung eine «Lichtgestalt» und einen «Titan» mit «übermenschlichem Pensum», aber er sprach auch die Teile seines Lebens an, in denen er umstritten war, Grenzen hatte und gescheitert ist. Mir erschien das Porträt stellenweise anrührend und mehr noch waren es die Fotos. Da wurde auch ein Mensch porträtiert - oder doch ein Held, nur eben ein typisch schweizerischer?

Der Streit um den Sewering-Nachruf ist neben der NS-Brisanz ein Clash zweier Kommunikationskulturen. Er hat auch viel mit dem aktuellen Medienwandel zu tun. Das Internet wird als Ort genutzt, sich weniger formalisiert zu verständigen. Im Blog des Deutschen Ärzteblatts wird über Sewering eher Tacheles geredet. Ein deutscher Landarzt postete in seinem freien Blog eine «Kropfleerete» über Sewerings «Arroganz und Überheblichkeit» zu Lebzeiten gegenüber den Hausärzten. Das sei zum Glück kein «Standardnachrufbla», meinte ein Kommentator. Blogname: «Der Landarsch» (www.landarsch.blogger.de). Andere Medien, andere Wörter.

Was wünschen Sie sich als Nachruf?

Eberhard Wolff* 